Original Research Paper

\title{
Hybrid Approach for Detection and Recognition of Vehicles
}

\author{
${ }^{1}$ Selvanayaki, K.S. and ${ }^{2}$ Rm. SomaSundaram \\ ${ }^{1}$ Department of Computer Applications, Easwari Engineering College, Chennai, India \\ ${ }^{2}$ Department of Computer Science, SNS College of Engineering, Coimbatore, India
}

\author{
Article history \\ Received: 24-02-2014 \\ Revised: 19-06-2014 \\ Accepted: 27-08-2014 \\ Corresponding Author: \\ Selvanayaki, K.S. \\ Department of Computer \\ Applications, Easwari Engineering \\ College, Chennai, India \\ Email: kssindia2004@yahoo.co.in
}

\begin{abstract}
On road vehicles have increased in numbers and monitoring them is a challenging task. In common areas of public crowd people and vehicles are common objects for monitoring. The proposed system aims at detecting number plate information indicating the possibility for security relevant issues. Existing system performs recognition mainly by using license plate alone. Addition of the features (logo, colour, shape) will increase the security of the system. Identification of the number plate region has been done by Blob detection method at the predefined aspect ratio. After detection, extraction of the number plate information using Eigen value regularization method. Further, two methodology included in this study are, identifying the tampered region in a car image either by extracting $\mathrm{HoG}$ feature in the spatial domain or block differences in DCT coefficients and their corresponding histogram in the transform domain respectively. Experimental results for the given car dataset describes the identification of the number plate region and tampered region quantitatively. The work presents detailed results of how the proposed approach gives better results using HoG approach. The approach gives good results in videos of cars recorded in frontal view in good lighting conditions. The paper in overall suggest a hybrid approach for detecting number plate information in cars taken in good lighting conditions.
\end{abstract}

Keywords: License Plate Detection, Character Extraction and Detection, Eigen Value Regularization, Histogram of Gradient (HoG), Discrete Cosine Transformation (DCT)

\section{Introduction}

In the field of video processing, digital video surveillance system plays a major part in monitoring interested objects (e.g., vehicles, people). The vehicles need to checked for security purposes (Petrovic and Cootes, 2004). Car recognition and classification is one such area in a video processing. In video containing vehicles, geometric properties will be used to distinguish car type vehicles from the other type of vehicles. License plate information can be used as a feature to distinguish different cars. But here number plate information cannot be used as a unique feature. The reason is that intruders might tamper a number plate. Therefore we need a technique to detect whether the number plate has been altered or not.
Other features considered for classification of cars are logo, shape, color, (Butzke et al., 2008; Kumar and Sivanandam, 2012). Vehicle can be identified automatically in roads and indoor in indstries. Real time recognition of vehicles faces many challenges like considering the object at different lighting conditions (Cucchiara and Piccardi, 1999), classifying the multiple cars of the same and different brands, capturing the video at different orientation of the camera, occlusion of the multiple cars (Koller et al., 1994) and considering the cars at the far distance.

Thus, Recognition of cars has one of its most important applications in surveillance systems, especially in buildings with tight security like parliament, other government offices. In such cases, we have to maintain a database system of frequently 
visiting cars that are allowed inside the office. A surveillance camera is placed at the entrance of the building that helps in identifying whether the incoming car is authenticated or not. If an unauthenticated car comes in, manual checking has to be performed.

This results in real time difficulty for security system to avoid unauthenticated vehicles from getting into secured premises. One of the challenges in implementing vehicle recognition and classification systems is to design a model that works across a wide variety of users and environments. Existing vehicle recognition system mainly uses license plate information as a feature for recognition (Deb et al., 2009; Conci et al., 2009; Ozbay and Ercelebi, 2005;
Cika et al., 2011). If it is tampered or replaced, effective system along with this feature has to be used for identifying whether the car is authenticated or not.

Figure 1 shows the complete set of steps proposed for number plate detection. The information in number plate in finally written to a text file for further processing.

\section{Related Work}

In this study the comparison of the approaches are done in consideration to moments as in Table 1, character recognition in Table 2, classifier in Table 3. The complete set of steps for the proposed number plate detection is shown in Fig. 1.

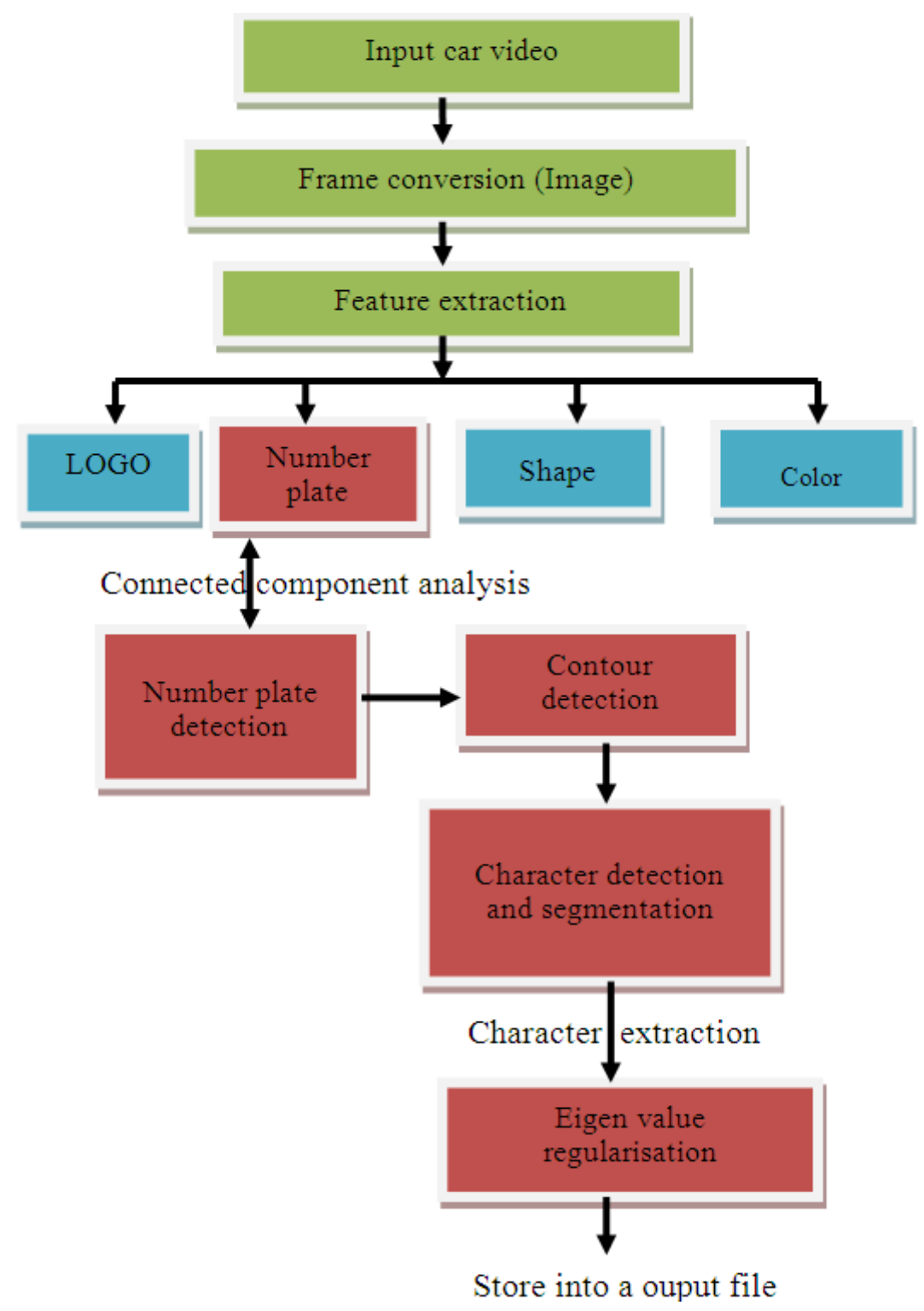

Fig. 1. The flowchart for proposed number plate detection and extraction 
Table 1. Comparison of different moment

\begin{tabular}{|c|c|c|c|c|}
\hline No & Types of moments & Category & Characteristics & Application \\
\hline 1 & Geometric moment & Moments of monomial basis & $\begin{array}{l}\text { 1. Efficient for image analysis } \\
\text { 2. Numerical Instability } \\
\text { 3. High sensitive to noise }\end{array}$ & $\begin{array}{l}\text { 1. Shape Analysis } \\
\text { 2. Image Normalization } \\
\text { 3. Colour texture recognition } \\
\text { 4. Object recognition }\end{array}$ \\
\hline 2 & Zernike moment & $\begin{array}{l}\text { Moments of continuous } \\
\text { orthogonal basis }\end{array}$ & $\begin{array}{l}\text { 1. Far robust to noise } \\
\text { 2. Numerical instabilities are rare } \\
\text { 3. It represents the property of an } \\
\text { image with no redundancy or } \\
\text { overlap between the moments with } \\
\text { different order and representation }\end{array}$ & $\begin{array}{l}\text { 1. Pattern recognition } \\
\text { 2. Content based image retrieval } \\
\text { 3. Object recognition }\end{array}$ \\
\hline 3 & Racah moment & $\begin{array}{l}\text { Moments of discrete } \\
\text { orthogonal } \\
\text { Basis function }\end{array}$ & $\begin{array}{l}\text { 1. It is kind of orthogonal } \\
\text { defined on a non-uniform lattice } \\
\text { 2. Immune to noise }\end{array}$ & $\begin{array}{l}\text { 1. Image retrieval } \\
\text { 2. Data compression }\end{array}$ \\
\hline 4 & $\begin{array}{l}\text { Radial-tchebichef } \\
\text { moment }\end{array}$ & $\begin{array}{l}\text { Moments of discrete } \\
\text { orthogonal basis }\end{array}$ & $\begin{array}{l}\text { 1. Eliminates the need for } \\
\text { transforming the coordinates } \\
\text { to the unit circle } \\
\text { 2. It also eliminates the need } \\
\text { for numerical approximation in their } \\
\text { numerical implementation } \\
\text { 3. Computationally less overhead }\end{array}$ & $\begin{array}{l}\text { 1. Shape feature extraction } \\
\text { 2. Invariant pattern recognition. }\end{array}$ \\
\hline
\end{tabular}

Table 2. Merits and demerits of different character recognition Techniques

\begin{tabular}{|c|c|c|c|c|c|}
\hline No & Author & Approach & Dataset Used & Merits & Demerits \\
\hline 1 & $\begin{array}{l}\text { Vlontzos and } \\
\text { Kung (1992) }\end{array}$ & $\begin{array}{l}\text { Hierarchical system } \\
\text { with Hidden } \\
\text { Markov Model }\end{array}$ & $\begin{array}{l}\text { 1. Bitmapped (screen) } \\
\text { fonts of an apple } \\
\text { macintosh PC. }\end{array}$ & $\begin{array}{l}\text { 1. Solves both the } \\
\text { context sensitivity } \\
\text { problem and the } \\
\text { character instantiation } \\
\text { problem }\end{array}$ & $\begin{array}{l}\text { 1. Large computational } \\
\text { requirements; } \\
\text { 2. Needs } \mathrm{O}(\mathrm{TN} 2) \text { for a } \mathrm{N} \\
\text { state model and } \mathrm{T} \\
\text { observations. } \\
\text { 3. Complex structure }\end{array}$ \\
\hline 2 & $\begin{array}{l}\text { Anagnostopoulos et al. } \\
\text { (2008) }\end{array}$ & $\begin{array}{l}\text { Probabilistic Neural } \\
\text { Network (PNN) }\end{array}$ & $\begin{array}{l}\text { 1. Alpha numeric characters } \\
\text { from car license plates }\end{array}$ & 1. High accuracy & $\begin{array}{l}\text { 1. Design of multilayer } \\
\text { network and computational } \\
\text { complexity }\end{array}$ \\
\hline 3 & $\begin{array}{l}\text { Kurozumi et al. } \\
\text { (1999) }\end{array}$ & $\begin{array}{l}\text { Eigen space method } \\
\text { based on class } \\
\text { features and multiple } \\
\text { discriminant analysis }\end{array}$ & 1. Facial image database & $\begin{array}{l}\text { 1. Higher correct } \\
\text { classification rates } \\
\text { even with less number } \\
\text { of eigen vectors }\end{array}$ & $\begin{array}{l}\text { 1. May not perform } \\
\text { well if within class } \\
\text { variation is large }\end{array}$ \\
\hline 4 & $\begin{array}{l}\text { Turk and Pentl } \\
\text { (1991) }\end{array}$ & Standard eigen space. & 1. Rectangular Iris Code & $\begin{array}{l}\text { 1. Lower dimensional } \\
\text { feature vectors, } \mathrm{m}<\mathrm{N} \text {. }\end{array}$ & 1. Low processing speed \\
\hline 5 & $\begin{array}{l}\text { Kumar et al. } \\
\text { (2012) }\end{array}$ & $\begin{array}{l}\text { Eigen value } \\
\text { regularization }\end{array}$ & $\begin{array}{l}\text { 1. Number plate } \\
\text { Recognisation }\end{array}$ & $\begin{array}{l}\text { 1. Reduces the occurrence } \\
\text { of the false detection rate } \\
\text { for small number of features } \\
\text { and limited training set }\end{array}$ & 1. Ti me complexity is more \\
\hline
\end{tabular}

Table 3. Merits and demerits of different classifiers

\begin{tabular}{|c|c|c|c|c|c|c|}
\hline \multicolumn{2}{|r|}{ No Author Name } & \multirow{2}{*}{$\frac{\text { Types of Classifier }}{\text { Adaboost Classifier }}$} & \multirow[b]{2}{*}{$\begin{array}{l}\text { Merit } \\
\text { 1. Very simple to Implement } \\
\text { 2. Does feature selection resulting } \\
\text { in relatively simple classifier } \\
\text { 3. Fairly good generalization } \\
\text { 4. Able to manage the } \\
\text { overfitting of the data. } \\
\text { 5. Robust to noise }\end{array}$} & \multirow[b]{2}{*}{$\begin{array}{l}\text { Limitations } \\
1 . \text { Requires more } \\
\text { calculation } \\
\text { 2. Requires } \\
\text { more memory. }\end{array}$} & \multirow{2}{*}{$\begin{array}{l}\text { Application } \\
\text { 1. Image Retrieval } \\
\text { 2. Object Classification }\end{array}$} & \multirow[b]{2}{*}{$\begin{array}{l}\text { Comments } \\
\text { 1. It is type of boosting algorithm } \\
\text { 2. It constructs strong classifier as } \\
\text { linear combination of weak } \\
\text { classifiers }\end{array}$} \\
\hline 1 & $\begin{array}{l}\text { Freund and } \\
\text { Schapire } \\
(1999)\end{array}$ & & & & & \\
\hline 2 & $\begin{array}{l}\text { Chen et al. } \\
\text { (2006) }\end{array}$ & $\begin{array}{l}\text { Support Vector } \\
\text { machine }\end{array}$ & $\begin{array}{l}\text { 1. It has less overfitting. } \\
\text { (handle by soft margin) } \\
\text { 2. Flexibilty in choosing } \\
\text { a hyperplane. } \\
\text { 3. Ability to handle } \\
\text { large feature set. }\end{array}$ & $\begin{array}{l}\text { 1. Choice of kernel. } \\
\text { (guassian sigmod etc.,) } \\
\text { 2. Choice of kernel } \\
\text { parameter } \\
\text { 3. Optimization criterion. }\end{array}$ & $\begin{array}{l}\text { 1. Hand writing analysis } \\
\text { 2. Face recognition }\end{array}$ & $\begin{array}{l}\text { 1. It is type of unsupervised } \\
\text { algorithm } \\
\text { 2. The training points are } \\
\text { taken as support vectors and } \\
\text { forms a hyperplane. } \\
\text { 3. If points are distributed } \\
\text { non uniformily,original input } \\
\text { space mapped into higher dimension } \\
\text { feature space where training set can } \\
\text { be separated. }\end{array}$ \\
\hline 3 & $\begin{array}{l}\text { Smach et al. } \\
(2006)\end{array}$ & Neural Approach & $\begin{array}{l}\text { 1. Highly robust } \\
\text { 2. It can identify unknown } \\
\text { patterns if trained properly }\end{array}$ & $\begin{array}{l}\text { 1. Difficulty in } \\
\text { identifying an } \\
\text { appropriate neural model. } \\
\text { 2. Misclassificati-on } \\
\text { treatment is not } \\
\text { effective enough. }\end{array}$ & $\begin{array}{l}\text { 1. Fingerprint } \\
\text { recognition } \\
\text { 2. Pattern recognition } \\
\text { 3. Speech recognition }\end{array}$ & $\begin{array}{l}\text { 1. It is type of supervised algorithm. } \\
\text { 2. Training process is generally slow. } \\
\text { 3. No preprocessing is required } \\
\text { since it normalisation is directly } \\
\text { involved in the weights. }\end{array}$ \\
\hline
\end{tabular}




\section{Character Recognition and Extraction:}

- It is inevitable part in license plate reading, document analysis

- Such a character recognising system requires the following characteristics

- High speed recognition

- Robustness for variety of character styles

\section{Proposed Work}

Given a video containing cars contour based approach is used for extracting the region of car. In the proposed method frame subtraction is done across consecutive frames. Feature extraction is then carried out in this extracted portion containing car. Features that are used to uniquely use in this proposed method is the Number plate. In the previous approaches, many algorithms have been proposed for extracting number plate information. Figure 2 shows the Proposed Number plate tamper Detection using Hog Descriptor.

Figure 3 shows the proposed number plate tamper detection using DCT coeffecients in a frequency domain. It is tested on a real time data set of a car captured in a frontal view.

Figure 4 shows the output of car's number plate detection using the proposed approach. The results after extracting the number plate information is displayed.

The results after tamper region extracton in spatial domain is shown in Fig. 5. The results are shown for a block difference of 31.66 and 35.62 .

The images that are taken into a consideration for processing the number plate can be either binary, gray scale or color (Anagnostopoulos et al., 2008; Hongliang and Changping, 2004; Zheng et al., 2005; Suryanarayana et al., 2005). Followed by the detection of the number plate, extraction of the characters from the detected number plate is very important. Many researchers have proposed the different algorithms to segment and extract the character (Nomura et al., 2005; Nijhuis et al., 1995; Franc and Hlaváč, 2005; Shyang-Lih et al., 2004; Kumar et al., 2012). Followed by the identification of the number plate, an authentication of the number plate information will be perform (Subramanyam and Emmanuel, 2012; Stamm and Liu, 2009; Wang et al., 2011; Muhammada et al., 2012).

\section{Number Plate Detection}

The steps involved in the Detection of the vehicle information are as follows (Kumar and Sivanandam, 2012; Suryanarayana et al., 2005).

\section{Smoothing}

Standard smoothing processes using the Gaussian filter.

\section{Morphological Operations (TOPHAT)}

TOPHAT is used for detecting the license plate considering the surroundings.

\section{Thresholding}

The light regions are shown prominently with a threshold above 120 to 255 .

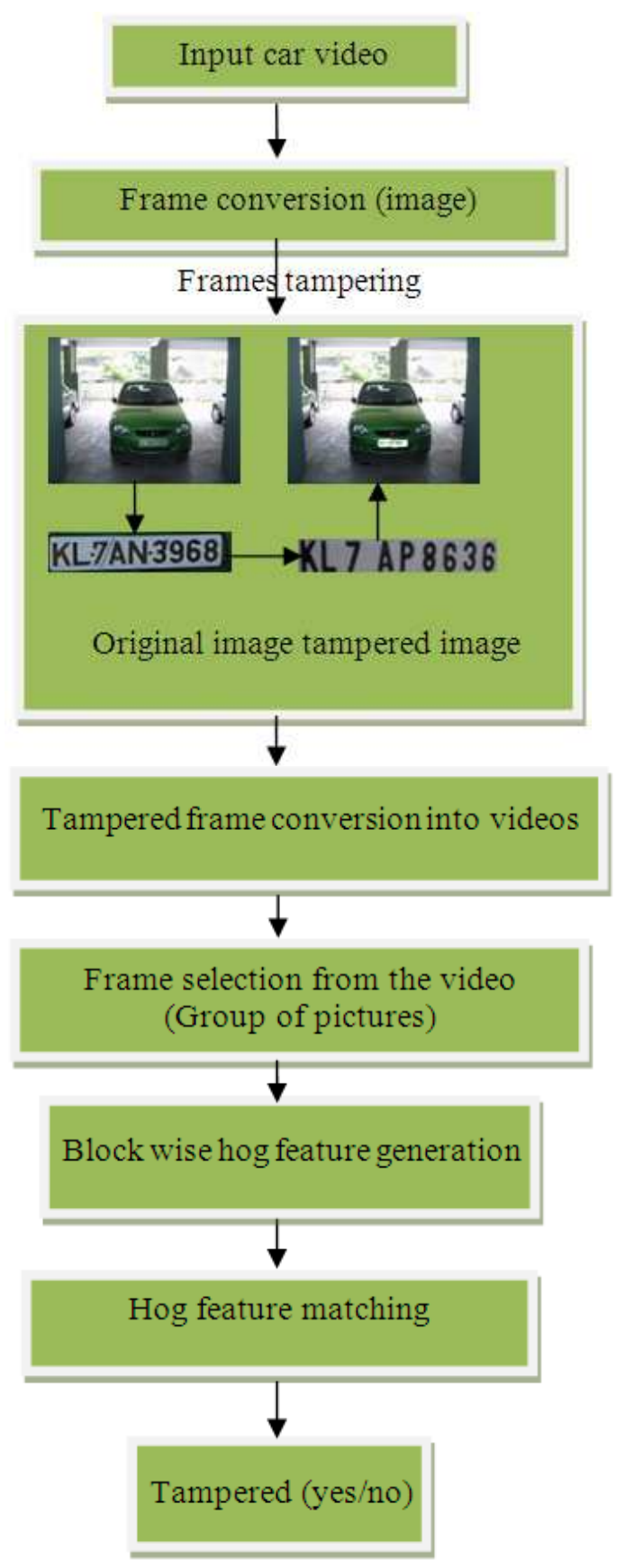

Fig. 2. The flow chart of proposed number plate tamper detection using hog descriptor (in spatial domain) 


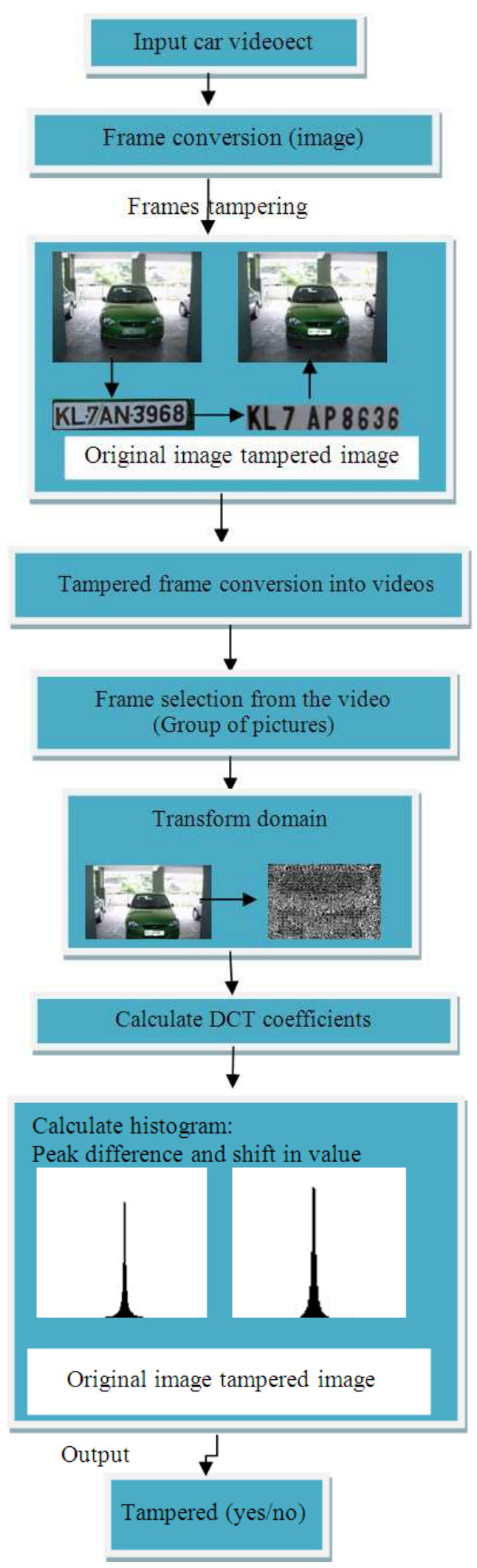

Fig. 3. The flow chart of proposed number plate tampers detection using DCT coefficients (in frequency domain)

\section{Blob Detection and Extraction}

Extracting the Blob of Area between 200 and 6000, Ratio between 4.0 and 10.0.

\section{Connected Component Analysis}

Perform pre-processing technique on the extracted number plate region and analyse the connected component in an image.

\section{Character Recognition (Training Phase)}

Before a segmentation of the characters from the detected and extracted number plate region, a system has to be trained with the alphanumeric characters as follow (Kumar et al., 2012).

\section{Collect Training Images}

Store the each sample of the character into their corresponding character classes (say samples (A, A, a) into the class ' $\mathrm{A}$ ').

\section{Calculate the Scatter Matrix}

Using the training images calculate the scatter matrix by the formula:

$$
S^{w}=\sum_{i=1}^{p} \frac{c_{i}}{q_{i}} \sum_{j=1}^{q i}\left(X_{i j}-\bar{X}_{l}\right)\left(X_{i j}-\bar{X}\right)^{T}
$$

Where:

$S^{w}=$ Within class scatter matrix

$q_{i}=$ Number of training samples in class $i$

$c_{i}=$ Class prior probability $c_{i}=\left(1 / p_{i}\right)$

$p=$ Equal probability

$X_{i j}=\mathrm{n}$-Dimensional Vector (wxh)

$X_{i}=$ Mean vector of training images

\section{Obtain Eigen Value and Vector}

From the constructed matrix, extract the eigen value and eigen vector of the dimension (D X D).

\section{Subspace Decomposition}

Categorize Eigen space into Character space, Noise space, Null space by specifying certain threshold values:

$$
\lambda_{m+1}^{g}=\max \left\{\forall \lambda_{k}^{g} \mid \lambda_{k}^{g}<\left(\lambda_{\text {med }}^{g}+\mu\left(\lambda_{\text {med }}^{g}-\lambda_{r}^{g}\right)\right)\right\}
$$

Where:

$$
\begin{aligned}
\lambda_{m+1}{ }^{g} & =\text { Median of an Eigen spectrum start point } m+1 \\
\lambda_{k}^{g} & =\text { Eigen value at the start point } k \\
\mu & =\text { Constant (always } 1) \\
\lambda_{\text {med }}{ }^{g} & =\text { Median of an Eigen spectrum from } k=1 \ldots . . r
\end{aligned}
$$




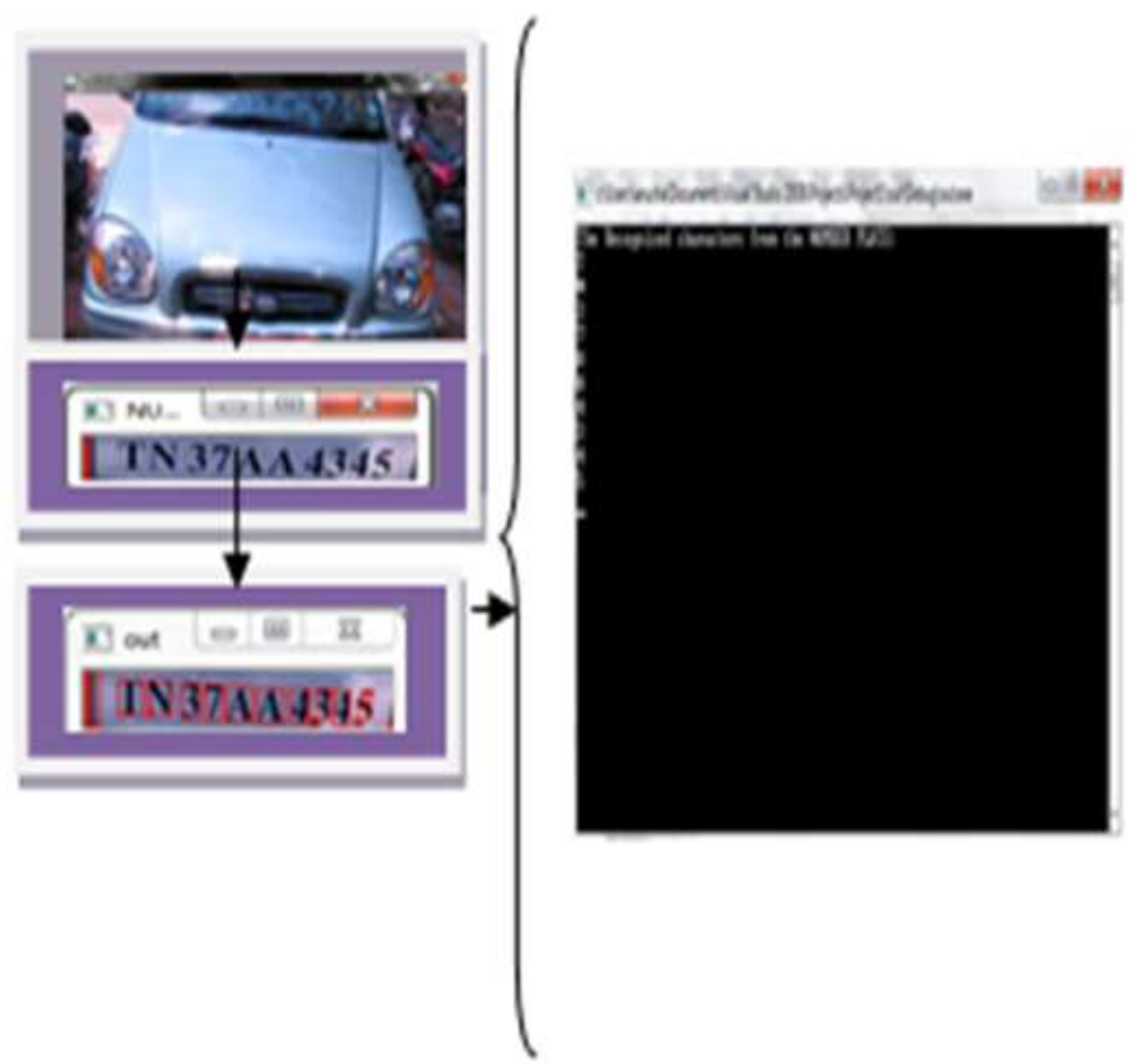

Fig. 4. Output of Car's Number plate Detection and Extraction

\section{Eigen Feature Regularization and Extraction}

Obtain the reduced matrix of dimension' $d$ ' and again calculate the sparse matrix:

$$
\tilde{\lambda}_{k}^{w}=\left\{\begin{array}{c}
\lambda_{k}^{w}, k<m \\
\frac{\alpha}{k+\beta}, m \leq k r \\
\frac{\alpha}{r+1+\beta}, r<k \leq n
\end{array}\right.
$$

Where:

$$
\lambda_{k}^{g} \quad=\text { Regularized region spectrum }
$$

$\alpha, \beta=$ Parameter

$K, m, n, r=$ Position of the Eigen Space

Class:

$$
\alpha=\frac{\lambda_{1}^{w} \lambda_{m}^{w}(m-1)}{\lambda_{1}^{w}-\lambda_{m}^{w}} \beta=\frac{m \lambda_{m}^{w}-\lambda_{1}^{w}}{\lambda_{1}^{w}-\lambda_{m}^{w}}
$$

\section{Character Recognition (Testing Phase)}

Detected characters in the number plate region can be given as an input into the trained system to recognise and extract the character. Those extracted characters are stored into a database for a further authentication process.

\section{Feature Vector Extraction}

Give an input character image (test image), extract the feature vector:

$$
\begin{aligned}
& F=U^{T} X, \\
& U^{T}=\Phi_{n}{ }^{w} \Phi_{d}{ }^{t}
\end{aligned}
$$

Where:

$$
\begin{aligned}
& F=\text { Dimension vector } \\
& U=\text { Extraction matrix } \\
& \Phi_{n}{ }^{w}=\text { Resulting Eigen vector matrix } \\
& \Phi_{d}{ }^{t}=\text { Reduced Eigen vector } \\
& X \quad=\text { Image vector }
\end{aligned}
$$




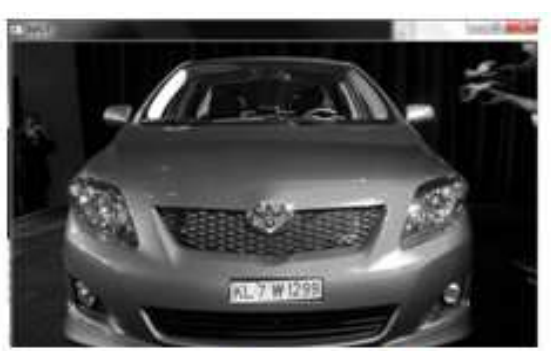

Input tampered car image

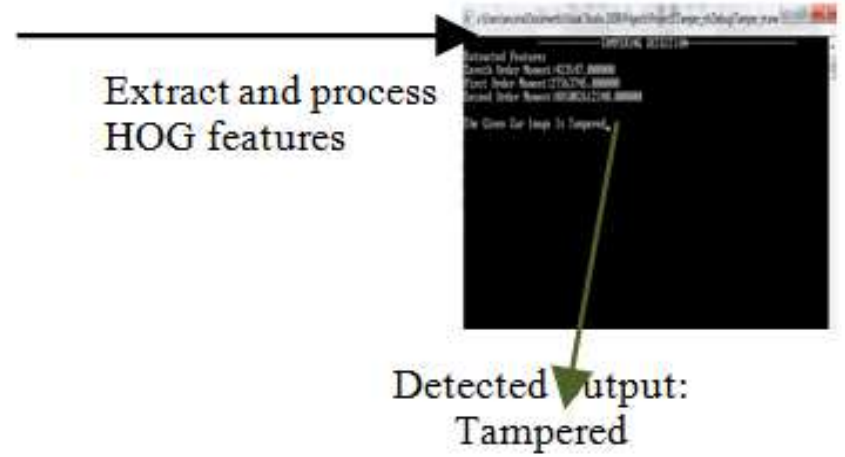

Block difference: 31.66
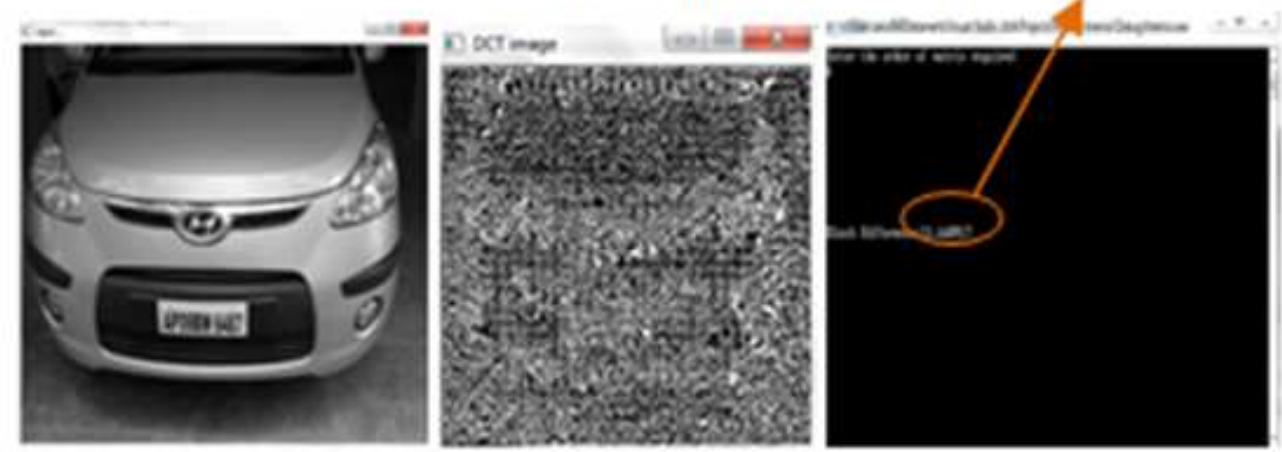

Block difference: 35.62
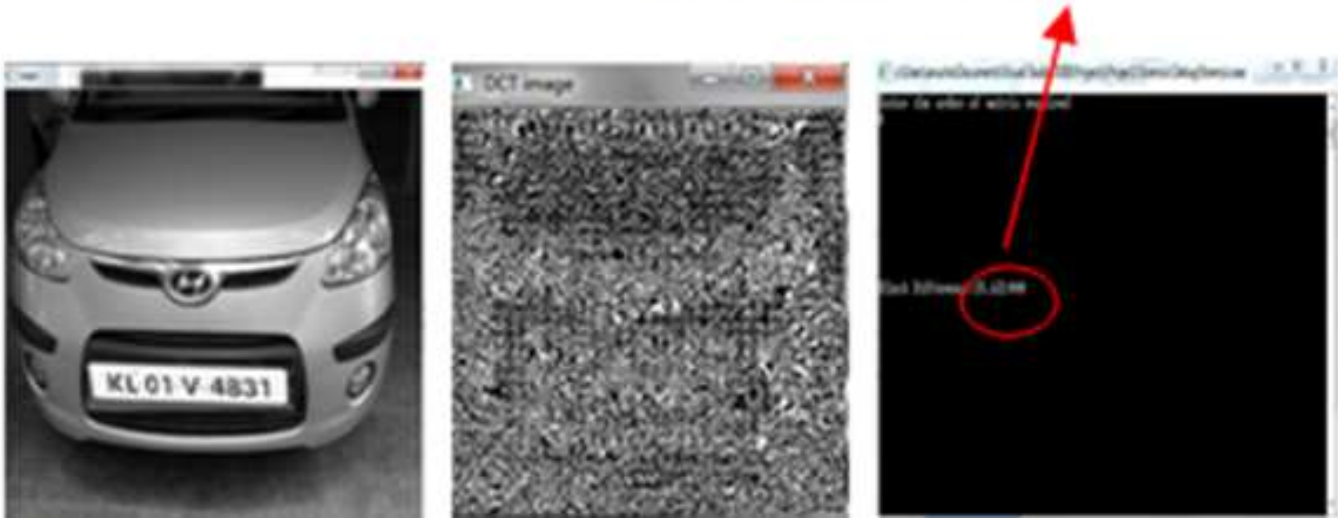

Fig. 5. Output of Tampering region in spatial domain using HOG feature

\section{KNN Classifier}

Compute the distance between test image and training images. Classify the input character image to the nearest value in the database and write to the output text file. Hence, extraction and detection of the number plate region has been done by performing the morphology operation and Eigen value regularization respectively. The extended proposed method of this study is to identify whether the detected number plate region is tampered or not using two different methodologies for further authentication.

\section{Number Plate Tamper Detection}

Here, identifying the detected number plate in the spatial domain as tampered or not using Hog descriptor. This method involves both the training and testing phase. In training phase, the system will be 
trained with the maximum untampered and tampered number plates. Those calculated values from the featured descriptor is fed into the system for supervise learning. Thus it makes the system to learn and able to discrete when the test image is given. Calculating the Hog features (Subramanyam and Emmanuel, 2012; Cao et al., 2011; Muhammada et al., 2012) has been explained as follows below.

\section{Tampering of the Frames (Licence Plate from other Videos)}

Perform copy-paste tampering on the converted original frames and again converted into a video.

\section{Extraction of HOG Features}

The extraction of HoG is done based on approaches proposed by (Subramanyam and Emmanuel, 2012; Cao et al., 2011; Muhammada et al., 2012).

Conversion of RGB into Gray scale Image:

$$
G(x, y)=[-101] * I(x, y)
$$

Compute the orientation at each pixel using horizontal and vertical gradient $\Theta(x, y)$-Orientation:

$$
\Theta(x, y)=\arctan \left(G_{y}(x, y) / G_{x}(x, y)\right)
$$

where, $G_{y}(x, y)$-Vertical gradient.

Divide the overlapping blocks of image $(\mathrm{N} \times \mathrm{N})$, further divided into $\mathrm{M} \times \mathrm{M}(\mathrm{M}<=\mathrm{N})$.

Calculate the weighted vote at the pixels having gradient magnitude and store into orientation bins $l$ :

$$
\begin{aligned}
& \Omega_{l}(x, y)=\left\{G(x, y) \text { if } \Theta(x, y) \varepsilon \text { bin }_{l,}\right. \\
& G(x, y)=\sqrt{G_{X}(x, y)^{2}+G_{X}(x, y)^{2}}
\end{aligned}
$$

Normalization of the features of all the cells in the blocks:

$$
f_{\text {Cell }}=\frac{\sum(x, y) \in \operatorname{Cell} \Omega l(x, y)+\epsilon}{\sum(x, y) \in \operatorname{Block} G(x, y)+\epsilon}
$$

$€$-infinitesimally small quantity

\section{Detection of Tamper}

Matching of HOG features of frames has to be performed by applying a certain threshold and detect whether the Number plate region has been tampered or Not.

\section{Number Plate Tampers Detection}

It is another methodology that has been proposed in the frequency domain that tells whether the number plate region has been tampered or not. It includes the calculation of the coefficient differences and1D histogram from the image that has been transformed into the frequency domain using DCT. It can be explained as follow (Stamm and Liu, 2009; Wang et al., 2011; Muhammada et al., 2012).

\section{Tampering of the Frames (Licence Plate from other Videos)}

Perform copy-paste tampering on the splitted original frames and again convert into a video.

\section{Performing Domain Transformation:}

- The image is broken into $8 \times 8$ blocks

- DCT is applied to each block:

$$
\begin{aligned}
& D(i, j)=\frac{1}{\sqrt{2 N}} C(i) C(j) \sum_{x=0}^{N-1} \sum_{y=0}^{N-1} p(x, y) \cos \left[\frac{(2 x+1) i \pi}{2 N}\right] \\
& \cos \left[\frac{(2 y+1) j \pi}{2 N}\right] C(u)=\left\{\begin{array}{l}
\frac{1}{\sqrt{2}} \text { if } u=0 \\
1 \quad \text { if } u>0
\end{array}\right\}
\end{aligned}
$$

- Each block is compressed through quantization

\section{Blocking Artifacts}

The differences between each block in the tampered image and the original image are foun in this phase.

\section{Detection of Tamper}

The differences of the tampered image will be higher than the original image's block differences. If the histogram is drawn for the original image and tampered image, the resultant will be the shift in frequency with respective to the energy.

\section{Results}

The hybrid approach proposed in the work has been tested and analyzed on the images of the vehicles. Here we have considered the car videos and images for number plate detection, extraction and tamper detection on the number plate respectively. The comparison of tampered and untampered region results are shown in Fig. 6. 

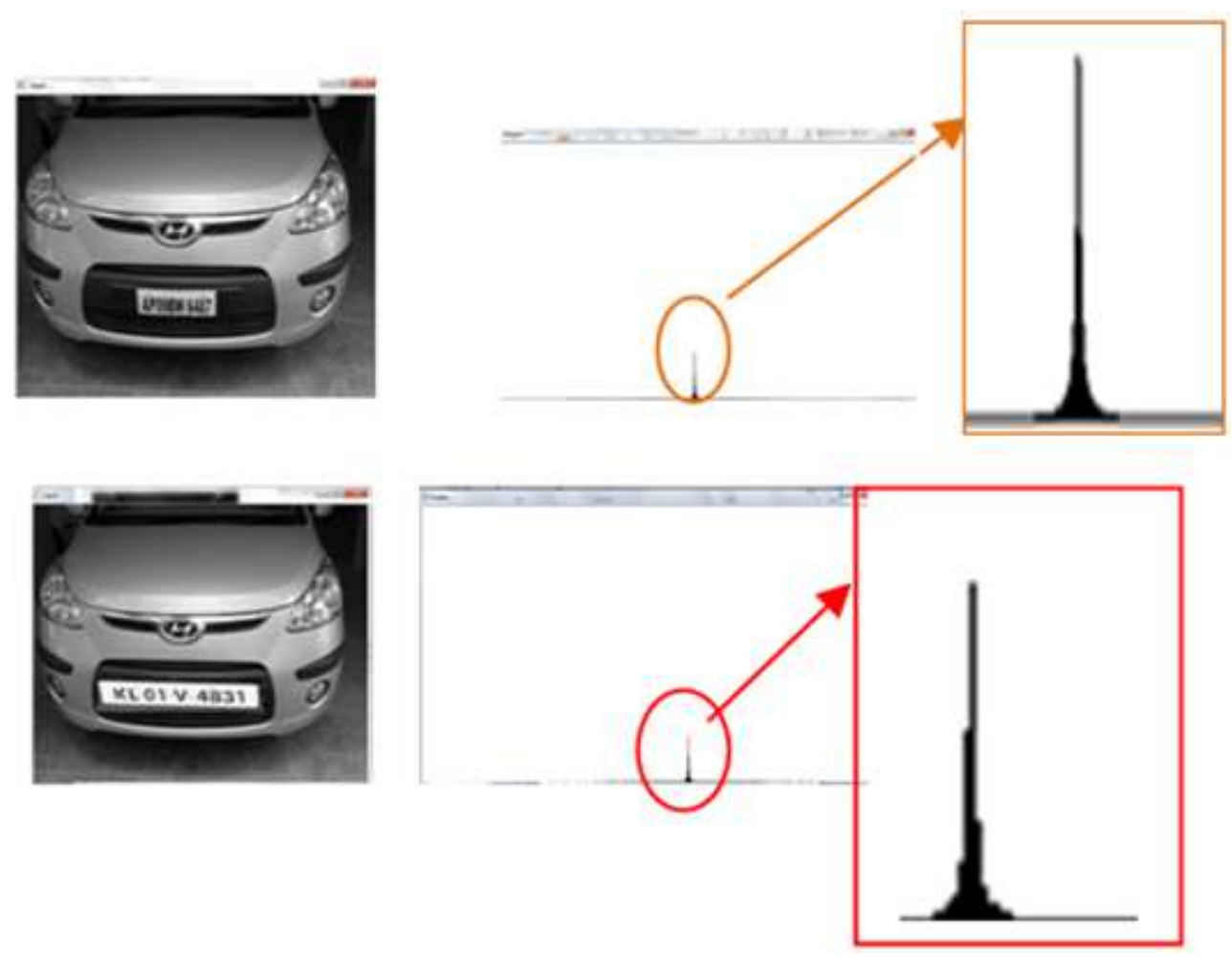

Fig. 6. Comparison of Tampered and untampered region using DCT coefficients and their Corresponding Histogram

\section{Conclusion}

In the above proposed method, the detection of a vehicle and identification of the number plate region of the car has been performed for a given video. After identification of the Number plate, characters on the number plate has recognized, extracted and stored in the text file. The second part of this study is to find whether the given number plate region has been tampered or not. Tampering detection had experimented in both spatial domain and frequency domain in which the basic inference of the tampered car image and original car image has been observed. The work does not work well for government vehicles as they carry information of logo of government emblems.

The future work can be extended to government vehicles carrying givernment logo. The work can be tested with videos taken in bad weather conditions. It can be tested on a video recorded from a mounted camera in a vehicle.

\section{Acknowledgement}

I would like to express my gratitude to all those who gave me these possibilities to submit the paper for the journal. I want to thank the Management,
Easwari Engineering College for their continuous support in the research. I extend my sincere thanks to Dr. D. Sivakumar, Head of the Department for his help. I thank my husband Mr. M.P. Sakthivel and my family members for their guidance, appreciation and support. Last but not the least I thank my almighty for the blessings.

\section{Author's Contributions}

All authors equally contributed in this work.

\section{Ethics}

This article is original and contains unpublished material. The corresponding author confirms that all of the other authors have read and approved the manuscript and no ethical issues involved.

\section{References}

Anagnostopoulos, C.N.E., I.E. Anagnostopoulos, I.D. Psoroulas, V. Loumos and E. Kayafas, 2008. License plate recognition from still images and video sequences: A survey. IEEE Trans. Intelli. Transportat. Syst., 9: 377-391.

DOI: 10.1109/TITS.2008.922938 
Butzke, M., A.G. Silva, M.D.S. Hounsell and M.A. Pillon, 2008. Automatic recognition of vehicle attribute-color classification and logo segmentation. Hifen Urugaiana, 32: 293-300.

Cao, X., C. Wu, P. Yan and X. Li 2011. Linear svm classification using boosting hog features for vehicle detection in low-altitude airborne videos. Proceedings of the 18th IEEE International Conference on Image Processing, Sept. 11-14, IEEE Xplore Press, Brussels, pp: 2421-2424. DOI: $10.1109 /$ ICIP.2011.6116132

Chen, L.T., M.J. Wang, C.J. Wang and H.M. Tai, 2006. Audio Signal Classification Using Support Vector Machines. In: Advances in Neural Networks, Wang, J., Z. Yi, J.M. Zurada, B.L. Lu and H. Yin (Eds.)., Springer Berlin Heidelberg, ISBN-10: 978-3-540-34437-7, pp: 188-193.

Cika, P., M. Zukal and M. Sebela, 2011. Vehicle license plate detection and recognition using symbol analysis. Proceedings of the 34th International Conference on Telecommunications and Signal Processing, Aug. 18-20, IEEE Xplore Press, Budapest, pp: 589-592. DOI: 10.1109/TSP.2011.6043661

Conci, A., J.E.R. De Carvalho and T.W. Rauber, 2009. A complete system for vehicle plate localization, segmentation and recognition in real life scene. IEEE Latin Am. Trans., 7: 497-506. DOI: 10.1109/TLA.2009.5361185

Cucchiara, R. and M. Piccardi, 1999. Vehicle detection under day and night illumination. Proceedings of the 3rd International ICSC Symposium on Intelligent Industrial Automation, (IIA' 99).

Deb, K., H.U. Chae and K.H. Jo, 2009. Vehicle license plate detection method based on sliding concentric windows and histogram. J. Comput., 4: 771-777. DOI: $10.4304 /$ jcp.4.8.771-777

Franc, V. and V. Hlaváč, 2005. License plate character segmentation using hidden markov chains. Proceedings of the 27th DAGM Conference on Pattern Recognition, (CPR' 05), ACM, SpringerVerlag Berlin, Heidelberg, pp: 385-392.

DOI: 10.1007/11550518_48

Freund, Y. and R.E. Schapire, 1999. A short introduction to boosting. J. Japanese Society Artificial Intelli., 14: 771-780.

Hongliang, B. and L. Changping, 2004. A hybrid license plate extraction method based on edge statistics and morphology. Proceedings of the 17th International Conference on Pattern Recognition, Aug. 23-26, IEEE Xplore Press, pp: 831-834.

DOI: $10.1109 /$ ICPR.2004.1334387
Koller, D., J. Weber and J. Malik, 1994. Robust multiple car tracking with occlusion reasoning. Proceedings of the 3rd European Conference on Computer Vision Stockholm, May 2-6, Springer Berlin Heidelberg, Sweden, pp: 189-196. DOI: $10.1007 / 3-540-57956-7-22$

Kumar, T.S. and S.N. Sivanandam, 2012. A modified approach for detecting car in video using feature extraction techniques. Eur. J. Sci. Res., 1: 134-144.

Kumar, T.S., S.N. Sivanandam, A. Ajay and P. Krishnakumar, 2012. An improved approach for character recognition in vehicle number plate using eigen feature regularisation and extraction method.

Kurozumi, T., Y. Shinza, Y. Kenmochi and K. Kotani, 1999. Facial individuality and expression analysis by eigenspace method based on class features or multiple discriminant analysis. Proceedings of the International Conference on Image Processing, Oct. 24-28, IEEE Xplore Press, Kobe, pp: 648652. DOI: 10.1109/ICIP.1999.821714

Muhammada, G., M. Hussain and G. Bebis, 2012. Passive copy move image forgery detection using undecimated dyadic wavelet transform. Digital Investigat., 9: 49-57. DOI: $10.1016 /$ j.diin.2012.04.004

Nijhuis, J.A.G., M.H.T. Brugge, K.A. Helmholt, J.P.W. Pluim and M.A. Westenberg et al., 1995. Car License plate recognition with neural networks and fuzzy logic. Proceedings of the IEEE International Conference on Neural Networks, Nov. 27-Dec. 01, IEEE Xplore Press, Perth, WA, pp: 2232-2236. DOI: $10.1109 /$ ICNN.1995.487708

Nomura, S., K. Yamanaka, O. Katai, H. Kawakami and T. Shiose, 2005. A novel adaptive morphological approach for degraded character image segmentation. Patt. Recognit., 38: 1961-1975. DOI: 10.1016/j.patcog.2005.01.026

Ozbay, S. and E. Ercelebi, 2005. Automatic vehicle identification by plate recognition. World Acad. Sci. Eng. Technol. Int. J. Electrical Robot. Electron. Commun. Eng., 1: 1422-1425.

Petrovic, V. and T. Cootes, 2004. Analysis of features for rigid structure vehicle type recognition. Proceedings of the British Machine Vision Conference, (MVC' 04), The University of Manchester Library, Kingston, pp: 587-596.

Shyang-Lih, C., C. Li-Shien, C. Yun-Chung and C. SeiWan, 2004. Automatic license plate recognition. IEEE Trans. Intelli. Transportat. Syst., 5: 42-53. DOI: 10.1109/TITS.2004.825086

Smach, F., M. Atri, J. Mitéran and M. Abid, 2006. Design of a neural networks classifier for face detection. J. Comput. Sci., 1: 124-125. DOI: 10.3844/jcssp.2006.257.260 
Stamm, M.C. and K.J.R. Liu, 2009. Forensic detection of image tampering using intrinsic statistical fingerprints in histograms. Proceedings of the Annual Summit and Conference on Asia-Pacific Signal and Information Processing Association, (IPA' 09), HUSCAP, Hokkaido University, pp: 563-572.

Subramanyam, A.V. and S. Emmanuel, 2012. Video forgery detection using hog features and compression properties. Proceedings of the 14th International Workshop on Multimedia Signal Processing, Sept. 17-19, IEEE Xplore Press, Banff, AB, pp: 89-94. DOI: 10.1109/MMSP.2012.6343421

Suryanarayana, P.V., S.K. Mitra, A. Banerjee and A.K. Roy, 2005. A morphology based approach for car license plate extraction. Proceedings of the Annual IEEE INDICON, Dec. 11-13, IEEE Xplore Press, pp: 24-27. DOI: 10.1109/INDCON.2005.1590116
Turk, M. and A. Pentland, 1991. Eigenfaces for recognition. J. Cognitive Neurosci., 3: 71-86. DOI: 10.1162/jocn.1991.3.1.71

Vlontzos, J.A. and S.Y. Kung, 1992. Hierarchical system with hidden markov model. IEEE Trans. Image Process., 4: 539-543.

Wang, W., J. Dong and T, Tan, 2011. Exploring DCT coefficient quantization effect for image tampering localization. Proceedings of the IEEE International Workshop on Information Forensics and Security, Nov. 29-Dec. 2, IEEE Xplore Press, Iguacu Falls, pp: 1-6. DOI: 10.1109/WIFS.2011.6123129

Zheng, D., Y. Zhao and J. Wang, 2005. An efficient method of license plate location. Patt. Recogn. Lett. 26: 2431-2438. DOI: 10.1016/j.patrec.2005.04.014 